\title{
Promoting Foundation Reading Skills With At-Risk Students
}

\author{
Ana Sucena*, Ana Filipa Silva and Cátia Marques \\ Research and Intervention Reading Centre, Polytechnic Institute of Porto, Porto, Portugal
}

This paper presents an early reading intervention program, the PPCL (Programa de Promoção das Competências Leitoras-Promoting Reading Skills Program). PPCL focuses on the promotion of reading foundation abilities-letter-sound, phonemic awareness, decoding, and spelling-with at-risk first graders. This study assessed the impact of PPCL on the reading foundation abilities with 311 first graders (173 boys and 138 girls), divided between intervention and comparative group (respectively, 206 and 105 first graders). Results were analyzed with an inter- (intervention and comparative group) and intra- (pre-and post-test) group design. A mixed two-way Manova indicated the presence of statistically significant differences between the two assessment moments, with the intervention group presenting higher values than the

OPEN ACCESS

Edited by:

Heikki Juhani Lyytinen,

Niilo Mäki institute, Finland

Reviewed by:

Angeliki Mouzaki,

University of Crete, Greece

Cláudia Cardoso-Martins,

Federal University of Minas Gerais,

Brazil

*Correspondence:

Ana Sucena

asucena@ess.ipp.pt

Specialty section:

This article was submitted to Educational Psychology, a section of the journal

Frontiers in Psychology

Received: 24 February 2021 Accepted: 11 June 2021

Published: 05 July 2021

Citation:

Sucena A, Silva AF and Marques $C$ (2021) Promoting Foundation Reading Skills With At-Risk Students.

Front. Psychol. 12:671733. doi: 10.3389/fpsyg.2021.671733 comparative group in all abilities at the post-test and also above the cutoff score in all variables, which indicates that at-risk students eventually concluded the school year with satisfactory levels of reading skills. On the other hand, the comparative group scored below the cutoff score in all variables. The magnitude of the effect on the intervention group was higher than the one observed in the comparative group. Reading promotion with PPCL significantly improved at-risk students reading skills. In future studies, the authors intend to follow up on reading and writing participants' skills.

Keywords: assessment, early reading program, letter-sound knowledge, phonemic awareness, decoding

\section{INTRODUCTION}

Reading and writing are indispensable skills, of crucial importance for equal opportunities (Blomert and Froyen, 2010). Impairments in reading and writing acquisition skills can seriously limit personal aspirations (Jeffes, 2016; Jamshidifarsani et al., 2019). Reading and writing acquisition are based on the learning rhythm, which is associated with the characteristics of the orthography in which the child acquires reading. The differences between orthographies regarding their consistency between graphemes and phonemes are the basis for the Orthographic Depth Continuum. The less transparent an orthography is, the greater the likelihood for children to experience difficulties, especially in the initial phase of reading acquisition. European Portuguese is considered an intermediate orthography thus allowing children to develop the reading foundations at a faster pace and experiencing fewer difficulties than English children for example (Sucena et al., 2009; Ziegler et al., 2010). English is an opaque orthography, with 44 phonemes (with more than 1,100 possible pronunciations) and 229 graphemes (Rao, 2018). As a result of the inconsistencies between graphemes and phonemes English speaking children need a longer learning period (two times longer) to acquire the reading foundations (Seymour et al., 2003). Unlike English, Portuguese 
orthography presents fewer inconsistencies between graphemes and phonemes-35 phonemes for 67 graphemes (Serrano et al., 2011). Even if Portuguese speakers acquire reading skills earlier and faster than English speakers, some Portuguese children still face difficulties and struggle to develop reading and spelling skills.

For reading acquisition to be possible, two fundamental basic skills must be developed: phonemic awareness and letter-sound knowledge (Seymour and Evans, 1999; Seymour et al., 2003; Sucena et al., 2009, 2015; Kyle et al., 2013; Viana and Sucena, 2014). Phonemic awareness, the ability to analyze sounds that constitute words, is crucial for reading acquisition and considered one of the most powerful predictors of reading and writing success (Snowling, 2014; Landerl et al., 2019). It facilitates the understanding of correspondences between phonemes and the corresponding letters (Hulme et al., 2012). Difficulties with phonemic awareness are more commonly found across students who enter the school from socially disadvantaged backgrounds (Zalewska-Łunkiewicz et al., 2016; Diuk et al., 2019), who have experienced difficulties with language development (BickfordSmith et al., 2005; Porta and Ramirez, 2019; Raspin et al., 2019), and/or at family risk of dyslexia (Pennington and Lefly, 2001). Research has also shown that training phonemic awareness results in significant gains in reading and spelling performance. In the same vein, the performance of spelling and decoding are strongly related to phonemic awareness and letter-sound knowledge (Taha and Saiegh-Haddad, 2015). When children enter the first grade with low levels of phonemic awareness and letter-sound knowledge there is an increased risk for reading and writing difficulties. It is thus of major importance to identify them as being at risk of developing learning difficulties and beginning a systematic intervention.

These findings provide the theoretical motivation for early reading intervention programs (Hatcher et al., 2006; Suggate, 2016). The most successful reading intervention programs combine phonological awareness training with structured reading explicit instruction (e.g., Hatcher et al., 1994; Lovett et al., 2003; Hatcher et al., 2006; Snowling and Hulme, 2011; Galuschka et al., 2019) using self-correction strategies (Williams et al., 2016). A meta-analysis assessment of the long-term effects of phonemic awareness shows that the impact of phonemic awareness interventions was maintained along the time and transferred to non-targeted skills such as letter-sound knowledge with consequences on reading comprehension (Suggate, 2016).

Interventions with the best results in reading skills are those occurring early, i.e., in kindergarten (Hatcher et al., 2004; Richardson and Lyytinen, 2014) or at the beginning of primary school (with 6 or 7-years old) (Wimmer and Mayringer, 2002; Saine et al., 2011). If reading disabilities are not addressed early with at-risk students, difficulties tend to generalize to other domains thus jeopardizing future knowledge acquisition (Raspin et al., 2019), exposing students to consecutive experiences of failure, thereby diminishing their motivation to learn (Lyytinen and Erskine, 2016). However, when these difficulties are identified early and lead to a prompt individualized or small group systematic and intensive intervention, the likelihood of reversing failure trajectories is very high (Lyytinen, 2008; Hall and Burns, 2018).
Such findings have in recent years led to recommendations for reading instruction. The OECD (Organisation for Economic Co-operation and Development) formulated recommendations to help constituent countries to find solutions that enable effective learning. In Portugal, the report of Rodrigues et al. (2017) recommends early and continuous intervention for reading and writing teaching, during the initial years of school, i.e., from 1st to 4th grade. It also recommends the development of diagnostic and intervention tools and the sharing of information resources, early diagnosis, and intervention methodologies to be used in conjunction with teaching strategies and individualized intervention by teachers (Rodrigues et al., 2017).

The implementation of such policies tends to provide students with solid reading foundational abilities, such as phonemic awareness and letter-sound knowledge at school entry. Research suggests the existence of a strong cause-effect relationship between children's prior knowledge (including phonological awareness and letter-knowledge) and success in reading and writing acquisition at first grade (Birgisdottir et al., 2020). It is well known that the way children begin formal schooling influences their school path (Stanovich, 1991). There is a tendency for those who begin the journey without difficulty to build successful paths. Conversely, for those whose beginning is marked by difficulties (at-risk students), there is a tendency for an increase in difficulties throughout schooling, with consequences on the motivation toward school and school learning (Lyytinen and Erskine, 2016). In this sense, the preparation of students for the reading acquisition should include phonemic awareness and letter-sound knowledge, especially so at the onset of first grade and preferably also at kindergarten.

In Portugal, more than $10 \%$ of children are retained in the 2nd grade mainly because of reading difficulties (e.g., Ferreira et al., 2015). This scenario is also found in other countries such as Luxemburg, Netherland, France and Spain (PISA, 2012). We can assume that the mainstream educational system still fails to support students at risk of developing learning disabilities. The opportunities usually given to students with learning disabilities are not enough for them to consolidate letter-sound knowledge, to develop effective spelling, decoding and reading fluency (Schaars et al., 2017; Duke and Mesmer, 2019). In this sense, international research has invested in the development and assessment of the impact of intervention projects that inform the educational practice, promoting the educational success of first graders (Niedo et al., 2014; López-escribano et al., 2014; Nagler et al., 2015; Shannon et al., 2015; Snellings et al., 2015; AlberMorgan et al., 2016; Ardoin et al., 2016; Hollands et al., 2016; Schneider et al., 2016; Horne, 2017; Madden and Slavin, 2017; Messer and Nash, 2017; Moser et al., 2017; Rosas et al., 2017; van de Ven et al., 2017; Solheim et al., 2018; Jamshidifarsani et al., 2019; Martens et al., 2019; Volkmer et al., 2019).

These studies show that successful reading interventions focus primarily on four major topics: phonemic awareness, decoding, fluency, and comprehension. Studies that used a comparative group revealed differences between the intervention and nonintervention groups, with more marked improvements in reading skills for the intervention group (e.g., Nagler et al., 2015; Horne, 2017; Messer and Nash, 2017; Rosas et al., 2017). Similar 
initiatives have been developed in Portugal. A report of PNPSE (Portuguese acronym for Programa Nacional de Promoção do Sucesso Escolar, in English National School Success Promotion Program) published in 2019, describes the projects implemented in Portuguese primary schools between 2016 and 2018 (in Portugal, the primary school system includes the 1 st to the 4 th grade). The report lists six projects on reading and writing acquisition (Verdasca et al., 2019). These projects focus on different reading competencies. Three of these projects focus on fluency and comprehension, one on phonemic awareness, letter-sound knowledge and decoding; no specific information is presented for the remaining. Three main axes can be highlighted from these projects: (i) tracking and monitoring (ii) consultancy, and (iii) intervention. Projects focusing on tracking and monitoring aim to track and monitor the students reading fluency and comprehension, by analyzing the students' performance during the school year. Projects focusing on consultancy aim to train the technical team, responsible for implementing the project, on the mastery of intervention strategies and follow-up the efficacy of their interventions. Finally, the intervention was the main goal of one of these projects, focusing on developing and implementing intervention strategies on phonemic awareness and letter-sound knowledge development, as well as the decoding process with speech therapists, psychologists and school teachers working full time in the project. This last project is the subject of analysis in the present study. As far as the authors' knowledge goes, this is the first study to present the intervention impact (using a comparative and intervention group) for a Portuguese reading promotion program.

\section{The PPCL}

This intervention program is part of a broader project, aiming not only at at-risk first graders but also kindergarteners. In this study, we focus on the at-risk first graders' intervention program. This program aims to intervene early with at-risk students promoting the alphabetic principle learning through phonemic awareness and letter-sound knowledge (pre-reading skills), as well as the spelling and decoding processes, which are the foundations for fluency and reading comprehension.

This program occurs daily, consisting of a hybrid intervention, adopting virtual and real environments, respectively, a reading acquisition software ("I read," four sessions per week, with a duration of $15 \mathrm{~min}$ each) and paper and pencil activities (one session per week, $45 \mathrm{~min}$ ). Sessions occur in the school context, within school time, out of the classroom, within small groups (maximum 5 students). In Table 1 we present the paper and pencil activities organized in twenty sessions through purposebuilt play-like materials.

Examples of the paper and pencil activities are: "I am a sound" or "Bingo." The first activity ("I am a sound") is intended to promote phonemic awareness: each student represents one sound. Student 1 represents the sound "rrrr"; Student 2 represents the sound "ffff"; Student 3 represents the sound "ssss" and finally, Student 4 represents the sound "zzzz." Next, one card at a time (with the phoneme representation) is shown. The student's

TABLE 1 | PPCL program: chronogram of activities, specifying specific goals.

\begin{tabular}{|c|c|c|c|}
\hline Session number & Month & Task name & Specific goal \\
\hline 1st session & November & Mascot and teacher presentation + Snack time syllable & Presentation and Syllabic division \\
\hline 2nd session & November & I am a sound & Phonemic Awareness (initial phoneme) and Letter-Sound Knowledge \\
\hline 3th session & December & Sounds wheel & Phonemic Awareness (initial phoneme) and Letter-Sound Knowledge \\
\hline 4th session & December & Find the word & Phonemic Awareness (initial phoneme) and Letter-Sound Knowledge \\
\hline 5th session & January & Snack time-phoneme & Phonemic Awareness (phonemic segmentation) \\
\hline 6th session & January & Sound detective & Phonemic Awareness (segmentation and phonemic fusion) \\
\hline 7th session & January & Goldfish letters & Letter-Sound Knowledge \\
\hline 8th session & January & Bingo Diphthongs & Alphabetical decoding \\
\hline 9th session & February & Bingo CV & Alphabetical decoding \\
\hline 10th session & February & Dice & Alphabetical decoding \\
\hline 11th session & February & Words domino & Alphabetical decoding \\
\hline 12th session & March & Words factory & Alphabetical decoding \\
\hline 13th session & March & Bingo figure-word & Alphabetical decoding \\
\hline 14th session & March & Bingo-simple words & Alphabetical decoding \\
\hline 15th session & March & $\begin{array}{l}\text { Words wheel (orthographic contextual rule: } \\
\text { intervocalic }<\mathrm{rr}>\text { and }<\mathrm{r}>\text { for/R/and } / \mathrm{r} \text { ) }\end{array}$ & Spelling decoding \\
\hline 16th session & April & $\begin{array}{l}\text { Complete the words (orthographic contextual rule: } \\
\text { intervocalic }<\mathrm{rr}>/<\mathrm{r}>\text { for/R/and/r/) }\end{array}$ & Spelling decoding \\
\hline 17th session & April & $\begin{array}{l}\text { Complete the words (orthographic contextual } \\
\text { rule: }<\text { ge/i }>\text { and }<\text { gue/i }>\text {; for/3/and/g/) }\end{array}$ & Spelling decoding \\
\hline 18th session & May & $\begin{array}{l}\text { Crosswords (orthographic contextual } \\
\text { rule: }<\mathrm{c}>\text { and }<\mathrm{c}>\text { for } / \mathrm{s} / \text { ) }\end{array}$ & Spelling decoding \\
\hline 19th session & May & $\begin{array}{l}\text { Wheel and bingo words (orthographic contextual } \\
\text { rule: }<\mathrm{s}>\text { and }<\mathrm{ss}>\text { for/z/and/s/) }\end{array}$ & Spelling decoding \\
\hline 20th session & May & Words Hopscotch & Spelling and Alphabetical decoding \\
\hline
\end{tabular}


task consists of verifying if the card starts with the sound they represent. The student representing the same sound as in the image is expected to raise her hand and say: "Sound!." The game ends when all students accumulate six cards with the same sound.

In the "Bingo" activity, which aims to promote the decoding process, the instructor distributes one game board per student and asks each one to read every word on their board; then, the instructor gives a word card to one student at a time and asks them to read it. This procedure is followed by all students. Students are asked to look for the corresponding word on their board. That student who has the word on his/her board marks it with the card above it. The game ends when all students complete their board. Each bingo has different goals-alphabet decoding (using words with simple graphemes) or orthographic decoding (using words with complex graphemes) (For a detailed description and examples on the Portuguese orthography, cf Sucena et al., 2009; Sucena and Castro, 2011).

Along with these twenty sessions, the same competencies are promoted in a virtual environment, along with forty sessions adopting the "I read" software (Sucena et al., 2019). In Table 2 we present the virtual activities developed using the "I read" software. This is a free use software for all children included in the project. The "I read" is recently child-friendly computer software. It aims to develop and train foundation reading and spelling skills through systematic training and with different games. Activities are presented to the child with increasing difficulty: simple items first (regarding both syllabic structure and orthographic complexity) and complex items later. Children at risk of experiencing difficulties reading acquisition, at the beginning of their school path, or children with special educational needs can specifically benefit from this computer software.

This study aims to present and evaluate the primary and main results of PPCL program implementation. A quasi-experimental design was adopted with two independent groups (intervention and comparative without intervention) and repeated measures (pre-and post-test).

\section{MATERIALS AND METHODS}

\section{Participants}

Participants at pre-test included 311 Portuguese first graders, 173 boys (55.6\%) and 138 girls (44.4\%), between 5 years and 7 months and 7 years and 3 months $(M=6.17, S D=0.83)$. Of these, 15 (2\%) come from a minority ethnic group (Romani), and 33 (5\%) have double nationality (born in Portugal but one foreign parent). For those with double nationality, it is important to emphasize that for 13 of them, the native language is Portuguese. The 311 participants were divided between the intervention group-206 (66.2\%) attending 28 schools in the northwest of Portugal, and the comparative group-105 (33.8\%) attending 20 schools in the northwest of Portugal. Participants were classified according to their socioeconomic background, $89(43.2 \%)$ students from medium-high SES and 117 students (56.8\%) from medium-low SES.
TABLE 2 | "I Read” tasks.

\begin{tabular}{|c|c|c|c|}
\hline General goals & Specific goals & $\begin{array}{c}\text { Number of } \\
\text { levels } \\
\text { (planets) }\end{array}$ & $\begin{array}{c}\text { Number of } \\
\text { games } \\
\text { (satellites) }\end{array}$ \\
\hline \multirow[t]{3}{*}{ Simple vocalic grapheme } & Phonemic awareness & 1 & 3 \\
\hline & $\begin{array}{l}\text { Letter-sound } \\
\text { knowledge }\end{array}$ & & \\
\hline & Alphabetical decoding & & \\
\hline \multirow[t]{2}{*}{ Oral diphthongs } & Phonemic awareness & 2 & 8 \\
\hline & Alphabetical decoding & & \\
\hline \multirow[t]{2}{*}{ Nasal diphthongs } & Phonemic awareness & 1 & 4 \\
\hline & Alphabetical decoding & & \\
\hline \multirow{3}{*}{$\begin{array}{l}\text { Simple consonant } \\
\text { grapheme }\end{array}$} & Phonemic awareness & 2 & 63 \\
\hline & $\begin{array}{l}\text { Letter-sound } \\
\text { knowledge }\end{array}$ & & \\
\hline & $\begin{array}{l}\text { Alphabetical spelling } \\
\text { and decoding }\end{array}$ & & \\
\hline \multirow{3}{*}{$\begin{array}{l}\text { Complex consonant } \\
\text { grapheme }\end{array}$} & Phonemic awareness & 4 & 37 \\
\hline & $\begin{array}{l}\text { Letter-sound } \\
\text { knowledge }\end{array}$ & & \\
\hline & $\begin{array}{l}\text { Orthographic spelling } \\
\text { and decoding }\end{array}$ & & \\
\hline
\end{tabular}

\section{Instruments}

Demographic variables were collected with the collaboration of the school staff (e.g., age, sex). The alphabetic principle was assessed through phonemic awareness and letter-sound knowledge (pre-reading skills). Decoding and spelling (reading and spelling skills) were assessed through isolated word and pseudoword reading and spelling tasks.

Specifically, phonemic awareness was assessed with two tasks-onset awareness (ALEPE-Portuguese acronym for Bateria de Avaliação da Leitura em Português Europeu, in English-European Portuguese Reading Assessment battery, Sucena and Castro, 2011) and phonemic segmentation. The onset awareness was evaluated through the Subtest of Initial Phoneme Metalinguistic Phonological Awareness of ALEPE, which consists of identifying the common phoneme in a couple of words. This subtest contains three training items and twelve experimental items. Each item consists of a pair of words, with two syllabic structures, namely CV [ConsonantVowel (open syllable) + CVC [Consonant-Vowel-Consonant (close syllable)]. The result is the total of correct answers. The critical value for the Subtest of Initial Phoneme Metalinguistic Phonological Awareness for the first grade is $80 \%$ (Sucena and Castro, 2011). Regarding Sucena and Castro (2011) a percentage of answers below the critical value alerts for an important gap in the performance of the assessed competence. This value was computed using a mean less than 1.5 Standard Deviation (Sucena and Castro, 2011). This is a common criterion adopted in the literature (e.g., Lezak et al., 2004). The phonemic segmentation was evaluated through one task that was built for that purpose, which consists of identifying the phonemes that constitute the word. The task is composed of two training items 


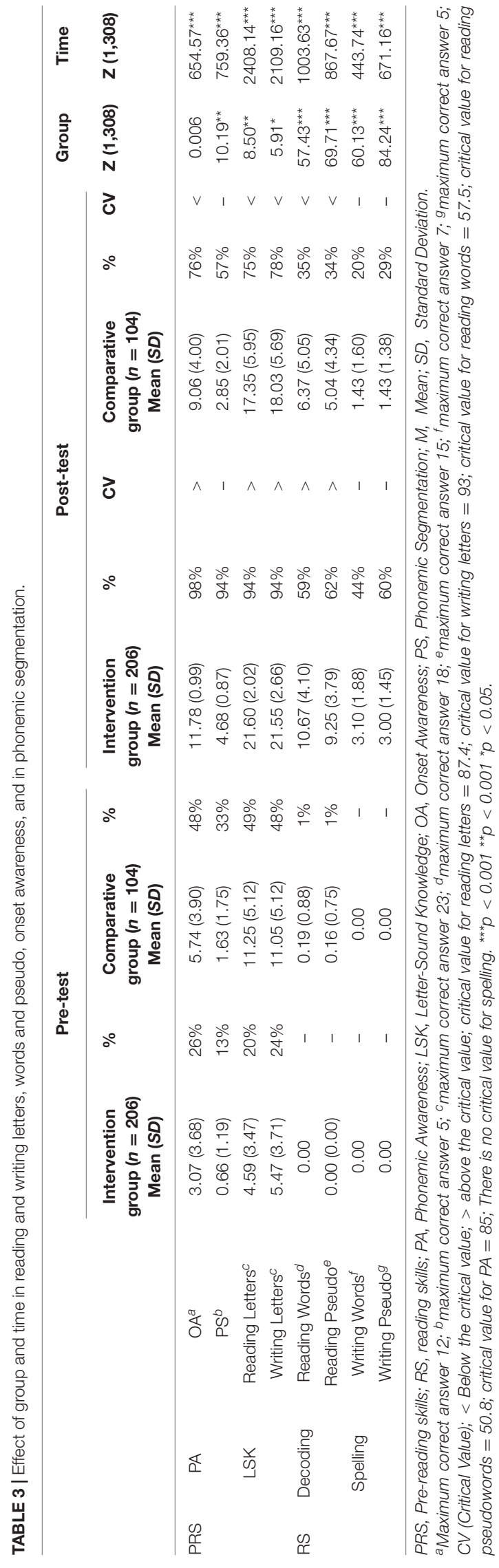

and five experimental items. Each item has the same syllable structure, namely VCV (Vowel-Consonant-Vowel). The result is the total of correct answers. There is no critical value for phonemic segmentation. Since there are no reference cutoff scores for Portuguese children on segmentation, the authors developed this task.

Letter-sound knowledge was evaluated through the Letters Reading Subtest and the Letters Spelling Subtest of ALEPE (Sucena and Castro, 2011). In the Letter Reading Subtest, the child is asked to read a list of letters (lowercase) displayed on the computer screen. This subtest consists of two training items and twenty-three experimental items. Both the sound and the letter name are accepted as correct answers. The training items are used only to guarantee that the child understands the task. The total result is the number of accurately identified letters. The critical value for first graders for reading letters is $87.4 \%$ (Sucena and Castro, 2011). In the Letter Spelling Subtest, the child is asked to spell letters dictated by the examiner (in lowercase format). This subtest consists of two training items and twentythree experimental items. The total result equals the total number of accurately spelt letters. The critical value for first graders for writing letters is $93 \%$ (Sucena and Castro, 2011).

Word and pseudoword naming tasks of ALEPE (Sucena and Castro, 2011) were adopted to assess the decoding process. The child is required to read a list of words/pseudowords that are presented one by one on a computer screen, each for a maximum of $10 \mathrm{~s}$. The stimuli list for first grade consists of four training items and eighteen experimental items. The items are composed of orthographically simple, consistent and inconsistent items for words and simple and consistent items for pseudowords. The critical value for the first grade is $57.5 \%$ for word naming and $50.8 \%$ for pseudowords. Cronbach's alphas for the ALEPE words/pseudowords scales ranged between 0.46 to first graders and 0.72 to 2 nd, $3^{\text {rd }}$, and 4 th graders (Sucena and Castro, 2011).

Spelling was evaluated in two different tasks, one for words $(n=7)$ and the other for pseudowords $(n=5)$, each stimulus dictated by the examiner. There are orthographically simple, consistent and inconsistent items for words and simple and consistent items for pseudowords. The result is the total number of accurately spelt items. Since there are no cutoff scores for Portuguese children on spelling, the authors developed these exploratory tasks.

\section{Procedures of Data Collection}

Authorizations were obtained from the school board and tutors. The objectives of the assessment were presented to both the school board and tutors, and the confidentiality of the data processing was guaranteed. Participants were administered the assessment tasks individually before and after the intervention, respectively, in September and in June 2019. The assessment team was constituted by eight reading and spelling training experts. The experts' team also implemented the intervention program. All elements of the expert team worked in close collaboration, as well as with the principal researcher. The role of the expert team was to implement the intervention program previously designed. Participants allocated to the intervention program were selected by their teachers following two criteria: 
(i) being at risk of developing reading learning disabilities and (ii) not having any extra intervention regarding reading and spelling abilities. Participants were assigned to the comparative or the intervention group according to their performance on the pre-reading competencies-phonemic awareness and/or lettersound knowledge. It was a deliberate option of the authors of this study to assign the students with the worst results to the intervention group. The cutoff point was determined at 1 Standard Deviation below the mean at (one or) the two tasks assessing phonemic awareness (and/or) letter-sound knowledge. Standards cutoffs are usually more conservative, ranging between 1.5 and 2 SD (Lezak et al., 2004). As the authors intended to identify at-risk children the option was to adopt a less conservative cutoff ( $1 \mathrm{SD}$ ), thus avoiding false negatives-to fail on identifying any at-risk children. Children in the comparative group followed the regular classes provided by the school teacher, whereas the intervention group benefited from the PPCL intervention along with the regular classes. There are no age differences between the intervention and the comparative groups. The proportion of students per SES was roughly equivalent: ca. $50 \%$ of the participants on both the intervention and the comparative group came from medium-high SES (specifically, 45 and 55\%). Both groups were exposed to the (same) Portuguese educational program for reading acquisition, based on phonics instruction. After the intervention, the school teacher of the comparative group benefited from specific training on lettersound, phonemic awareness, decoding and spelling strategies. Also, children allocated to the comparative were given free access to the "I Read" software.

\section{Data Analysis Procedures}

Statistical analyses were performed through the Statistical Package for the Social Sciences (SPSS IBM) for Windows, version 25.0. A Two-Way MANOVA was conducted to analyze the group and time effect on the assessment dimensions. Before running this statistical test, we verified the fulfillment assumptions. The multivariate normality was not fulfilled. The homogeneity of variance-covariance matrices, verified by Levene and Box tests, was not fulfilled. The absence of uniqueness assumption was assured. The absence of multicollinearity is not fulfilled, since not all the correlations are less than 0.80 (Tabachnick and Fidell, 2013). The correlation between the letter spelling and the letter reading dimensions is 0.86 . The sphericity assumption, verified by Bartlett's test, was not fulfilled. The independence of the observations was ensured in the data collection procedures. To control for biases derived from the non-fulfilment Two-Way MANOVA assumptions, the value of Pillai's Trace was considered (Tabachnick and Fidell, 2013). Cohen's $d$ was also calculated with the correction of Hedges and Olkin (1985), to evaluate the magnitude of the effect.

\section{RESULTS}

The inspection of the descriptive analyses reveals that at the pre-test, the comparative group performed better on pre-reading skills than the intervention group (around two times better); as for the reading skills the results are around zero for both the comparative group and the intervention group (cf. Table 3). At the post-test, the intervention group performed (i) better than the comparative group, both on pre-reading and reading skills, and (ii) above the critical value in all variables, whereas the comparative group scored below the critical value (in all variables).

The results of the Two-Way MANOVA indicate a statistically significant multivariate main effect for both time, Pillai Trace $=0.924, Z(8,301)=456.22, p<0.001$, partial eta squared $=0.924$, and group, Pillai Trace $=0.428, Z(8$, $301)=28.17, p<0.001$, partial eta squared $=0.428$, for all dimensions. There is also a multivariate main effect of the interaction between time and group in the evaluated dimensions, Pillai Trace $=0.712, Z(8,301)=92.89, p<0.001$, partial eta squared $=0.712$.

Univariate tests show that the time factor has a statistically significant effect on pre-reading skills: Phonemic Awareness [onset awareness, $Z(1,1.0)=654.57, p<0.001$, partial eta squared $=0.680$, phonemic segmentation, $Z(1,1.0)=759.36$, $p<0.001$, partial eta squared $=0.711$ ], and on Letter-Sound Knowledge [reading letters $Z(1,1.0)=2408.14, p<0.001$, partial eta squared $=0.887$, writing letters $Z(1,1.0)=2109.16, p<0.001$, partial eta squared $=0.873$, as well as in reading skills: Decoding $[$ (reading words $Z(1,1.0)=1003.63, p<0.001$, partial eta squared $=0.765$, reading pseudo $Z 1,1.0)=867.67, p<0.001$, partial eta squared $=0.738$ ], and on Spelling [writing words $Z(1$, $1.0)=443.74, p<0.001$, partial eta squared $=0.590$, writing pseudo $Z(1,1.0)=671.16, p<0.001$, partial eta squared $=0.685]$. Students have significantly higher values in these dimensions in the post-test as compared to the pre-test.

In addition, results indicate that the group factor has a statistically significant effect on pre-reading skills: [phonemic segmentation, $Z 1,308)=10.19, p=0.002$, partial eta squared $=0.032$ ] and Letter-Sound Knowledge [reading letters, $Z(1,308)=8.50, p=0.004$, partial eta squared $=0.027$, writing letters, $Z(1,308)=5.91, p=0.02$, partial eta squared $=0.019$ ], as well as on reading skills: Decoding [reading words, $Z(1$, $308)=57.43, p<0.001$, partial eta squared $=0.157$, reading pseudo, $Z(1,308)=69.71, p<0.001$, partial eta squared $=0.185]$, and on Spelling [writing words, $Z(1,308)=60.13, p<0.001$, partial eta squared $=0.163$, writing pseudo, $Z(1,308)=84.24$, $p<0.001$, partial eta squared $=0.215]$. Students from the intervention group presented significantly higher values than those in the comparison group in the post-test. Comparison group students show significantly higher values than the ones in the intervention group on pre-test.

Post hoc tests indicate that the intervention group performed better than the comparative group on both pre-reading and reading skills; both groups revealed the same pattern of evolution, i.e., pre-reading as well as reading skills improved during the time, specifically in phonemic segmentation, Letter-Sound Knowledge (reading and writing letters), Decoding (reading words and pseudo), and Spelling (writing words and pseudo).

The magnitude of the effect between groups ( $d$ Cohen values) was analyzed with Hedges and Olkin correction (1985). d 
Cohen varies between 3.23 (phonemic segmentation) and 5.99 (reading letters) for the intervention group whereas in the comparative group varies between 0.70 (decoding) and 1.71 (reading letters).

\section{DISCUSSION AND CONCLUSION}

This study sought to present the PPCL program and assess the primary and main results of its implementation. This program, like other international early reading interventions (e.g., Solheim et al., 2018; Jamshidifarsani et al., 2019), aims to promote pre-reading and reading skills with at-risk students, namely: knowledge of the alphabetic principle, through phonemic awareness and letter-sound knowledge, and the decoding and spelling processes, through word and pseudoword naming and spelling. A quasi-experimental design was adopted, with two independent groups (intervention and comparison without intervention) and repeated measures (pre-and posttest).

Both the intervention and the comparative group started 1st grade (pre-test) with low results (below 50\%) on prereading skills, as would be predictable (Schaars et al., 2017). At the pre-test, both groups scored better on letter-sound knowledge and onset awareness tasks than on the remaining ones. Reading skills results were null as would be expected at the onset of first grade (Sucena and Castro, 2011). These results indicate some preparation for reading acquisition during preschool years, probably focusing on the knowledge of isolated letters. It seems that the students whose performance in letter spelling stands out have received training in letter spelling before entering first grade, although not so regarding phonemic awareness.

At the pre-test, the comparative group had significantly better results than the intervention group regarding prereading skills. Indeed, as previously noted it was the intention of the authors of this study to assign those students with the worst results to the intervention group. Once, due to the financial restrictions, it was not possible to include all children in the intervention program. As children in both groups started the school year with null or very low reading skills, it would be expectable to find a progression curve regarding those skills, which could be more or less pronounced according to variables such as language development, family risk of dyslexia, mother's education, number of books at home, and/or family's socioeconomic status (Pennington and Lefly, 2001; Bickford-Smith et al., 2005; Zalewska-Łunkiewicz et al., 2016; Porta and Ramirez, 2019; Raspin et al., 2019). The outcome expected at the end of the first grade is far more ambitious than performing significantly better than at the onset of the school year though. At the end of first grade, children are expected to have consolidated not only phonemic awareness and letter-sound knowledge but also to master the decoding process.

Indeed, at the post-test, the intervention group performed (i) above $50 \%$ in all dimensions (except for spelling words) and (ii) results are above the critical value in all dimensions, which indicates that these (once at risk) students are finishing the school year with satisfactory levels of reading skills (Kyle et al., 2013; Sucena et al., 2015).

The impact of the intervention was validated by three main results: (i) the intervention group started the school year with worse results than the comparative group and finished the school year with results significantly above of the comparative group, which has also been verified and reported by other authors (e.g., Nagler et al., 2015; Horne, 2017; Messer and Nash, 2017; Rosas et al., 2017), (ii) at the end of the first grade the intervention group performed above the critical values, in contrast to the comparative group whose results were below the critical values, and (iii) the magnitude of the effect is higher for the intervention group than for the comparative group. These results are consistent with those obtained with other programs that adopt a similar strategy and which have been applied in different schools in Portugal (e.g., Verdasca et al., 2019), as well as internationally (e.g., Ardoin et al., 2016; Hollands et al., 2016; Messer and Nash, 2017; Solheim et al., 2018; Jamshidifarsani et al., 2019; Martens et al., 2019; Volkmer et al., 2019). Even if those national programs do not use a quasi-experimental design with two independent groups (intervention and comparison without intervention) as this study use. By comparing pre-reading and reading skills between Portuguese children at risk of experience reading difficulties (subject and not subject to intervention), and by comparing their performance against 1st-grade critical values, we hope to have contributed to the first of many studies, assessing the impact of Portuguese reading promotion programs, and emphasizing the need to pursue scientifically informed strategies in reading intervention.

Despite the relevance of implementing an intervention program with a group of children at risk, it is worth mentioning one main limitation. The criteria for selecting the students for the intervention and the comparative group did not ensure equivalent groups and therefore the interpretation of the results should be taken with caution.

In future studies, it is important to guarantee that the selection criteria adopted ensure equivalent groups selection to be able to assess the effectiveness of the intervention. Even though it is important to highlight that a group with real and strong intervention needs did benefit from this intervention, with great educational and social implications.

Moreover, since at the post-test the comparison group scored below the critical value, it was the authors' option to compensate the comparative group, for which teachers were invited to implement the PPCL in their classroom. In order to attain this goal school teachers of the comparative group have benefited from specific training on letter-sound, phonemic awareness, decoding and spelling strategies, accompanied by free access to the "I Read" software. Future research should assess the impact of maternal and/or paternal education on reading difficulties.

In conclusion, the PPCL methodology shows positive effects. It is expected that PPCL will help prevent early reading acquisition failure by promoting confident learners, willing to be fluent readers. 


\section{DATA AVAILABILITY STATEMENT}

The raw data supporting the conclusions of this article will be made available by the authors, without undue reservation.

\section{ETHICS STATEMENT}

Ethical review and approval was not required for the study on human participants in accordance with the local legislation and institutional requirements. Written informed consent to participate in this study was provided by the participants' legal guardian/next of kin.

\section{REFERENCES}

Alber-Morgan, S., Joseph, L., Kanotz, B., Rouse, C., and Sawyer, M. (2016). The effects of word box instruction on acquisition, generalization, and maintenance of decoding and spelling skills for first graders. Educ. Treat. Child. 39, 21-43.

Ardoin, S., Binder, K., Foster, T., and Zawoyski, A. (2016). Repeated versus wide reading: a randomized control design study examining the impact of fluency interventions on underlying reading behavior. J. Sch. Psychol. 59, 13-38. doi: 10.1016/j.jsp.2016.09.002

Bickford-Smith, A., Wijayatilake, L., and Woods, G. (2005). Evaluating the effectiveness of an early year's language intervention. Educ. Psychol. Pract. 21, 161-173. doi: 10.1080/02667360500205859

Birgisdottir, F., Gestsdottir, S., and Geldhof, G. J. (2020). Early predictors of first and fourth grade reading and math: the role of self-regulation and early literacy skills. Early Child. Res. Q. 53, 507-519. doi: 10.1016/j.ecresq.2020.05.001

Blomert, L., and Froyen, D. (2010). Multi-sensory learning and learning to read. Int. J. Psychophysiol. 77, 195-204. doi: 10.1016/j.ijpsycho.2010.06.025

Diuk, B., Barreyro, J. P., Ferroni, M., Mena, M., and Serrano, F. (2019). Reading difficulties in low-SES children: a study of cognitive profiles. J. Cogn. Dev. 20, 75-95. doi: 10.1080/15248372.2018.1545656

Duke, N., and Mesmer, H. (2019). Phonics faux pas: avoiding instructional missteps in teaching letter-sound relationships. Am. Educator 42, 12-16.

Ferreira, A. S., Ferreira, A. L., Justino, D., Flores, I., Santos, R., and Casas-Novas, T. (2015). Q2 - Chumbar Melhora as Aprendizagens?. Available Online at: http:// www.aqeduto.pt/q2-chumbar-melhora-as-aprendizagens/ (accessed April 24, 2021).

Galuschka, K., Görgen, R., Kalmar, J., Stefan Haberstroh, S., Schmalz, X., and Schulte-Körne, G. (2019). Effectiveness of spelling treatment approaches for learners with dyslexia - a meta-analysis and systematic review. Educ. Psychol. 55, 1-20. doi: 10.1080/00461520.2019.1659794

Hall, M., and Burns, M. (2018). Meta-analysis of targeted small-group reading interventions. J. Sch. Psychol. 66, 54-66. doi: 10.1016/j.jsp.2017.11.002

Hatcher, P. J., Hulme, C., Miles, J. N., Carroll, J. M., Hatcher, J., Gibbs, S., et al. (2006). Efficacy of small group reading intervention for beginning readers with reading-delay: a randomised controlled trial. J. Child Psychol. Psychiatry 47, 820-827. doi: 10.1111/j.1469-7610.2005.01559.x

Hatcher, P., Hulme, C., and Ellis, A. (1994). Ameliorating early reading failure by integrating the teaching of reading and phonological skills: the phonological linkage hypothesis. Child Dev. 65, 41-57. doi: 10.2307/1131364

Hatcher, P., Hulme, C., and Snowling, M. (2004). Explicit phoneme training combined with phonic reading instruction helps young children at risk of reading failure. J. Child Psychol. Psychiatry 45, 338-358. doi: 10.1111/j.14697610.2004.00225.x

Hedges, L., and Olkin, I. (1985). Statistical Methods for Meta-Analysis. San Diego: Academic Press.

Hollands, F., Kieffer, M., Shand, R., Pan, Y., Cheng, H., and Levin, H. (2016). Cost-effectiveness analysis of early reading programs: a demonstration with recommendations for future research. J. Res. Educ. Eff. 9, 30-53. doi: 10.1080/ 19345747.2015.1055639

Horne, J. K. (2017). Reading comprehension: a computerized intervention with primary-age poor readers. Dyslexia 23, 119-140. doi: 10.1002/dys.1552

\section{AUTHOR CONTRIBUTIONS}

AS designed, supervised all the study, and also revised the article critically. CM analyzed the data and wrote the manuscript. AFS collected and insert the data on SPSS. All authors contributed to the article and approved the submitted version.

\section{FUNDING}

This work was supported by European Horizon 2020, under OPERAÇÃO NORTE-08-5266-FSE349 000095.

Hulme, C., Bowyer-Crane, C., Carroll, J., Duff, F., and Snowling, M. (2012). The causal role of phoneme awareness and letter-sound knowledge in learning to read: combining intervention studies with mediation analyses. Psychol. Sci. 23, 572-577. doi: 10.1177/0956797611435921

Jamshidifarsani, H., Garbaya, S., Lim, T., Blazevic, P., and Ritchie, J. (2019). Technology-based reading intervention programs for elementar grades: an analytical review. Comput. Educ. 128, 427-451. doi: 10.1016/j.compedu.2018. 10.003

Jeffes, B. (2016). Raising the reading skills of secondary-age students with severe and persistent reading difficulties: evaluation of the efficacy and implementation of a phonics-based intervention programme. Educ. Psychol. Pratice 32, 73-84. doi: 10.1080/02667363.2015.1111198

Kyle, F., Kujala, J., Richardson, U., Lyytinen, H., and Goswami, U. (2013). Assessing the effectiveness of two theoretically motivated computer-assisted reading interventions in the United Kingdom: GG Rime and GG Phoneme. Read. Res. Q. 48, 61-76. doi: 10.1002/rrq.038

Landerl, K., Freudenthaler, H., Heene, M., De Jong, P., Desrochers, A., Manolitsis, G., et al. (2019). Phonological awareness and rapid automatized naming as longitudinal predictors of reading in five alphabetic orthographies with varying degrees of consistency. Sci. Stud. Read. 23, 220-234. doi: 10.1080/10888438. 2018.1510936

Lezak, M. D., Howieson, D. B., Loring, D. W., Hannay, H. J., and Fischer, J. S. (2004). Neuropsychological Assessment, 4th Edn. Oxford: Oxford University Press.

López-escribano, C., Sánchez-Hípola, P., Suro Sánchez, J., and Leal Carretero, F. (2014). Comparative analysis of rapid automatized naming studies in Spanish and reading acquisition and reading difficulties. Universitas Psychol. 13, 757769.

Lovett, M., Barron, R., and Benson, N. (2003). "Effective remediation of word identification and decoding difficulties in school-age children with reading disabilities," in Handbook of Learning Disabilities, eds H. L. Swanson, K. Harris, and S. Grahan (New York, NY: Guilford Press), 273-292.

Lyytinen, H. (2008). New Technologies and Interventions for Learning Difficulties: Dyslexia in Finnish as a Case Study, in Foresight Mental Capital and Wellbeing Project: The Government Office for Science. London, UK: Government Office for Science.

Lyytinen, H., and Erskine, J. (2016). "Early identification and prevention of reading problems," in Encyclopedia on Early Childhood Development, eds D. P. Fromberg and L. R. Williams (Milton Park: Routledge).

Madden, N. A., and Slavin, R. E. (2017). Evaluations of technology-assisted smallgroup tutoring for struggling readers. Read. Writ. Q. 33, 1-85577. doi: 10.4135/ 9781452219042.n1

Martens, B., Young, N., Mullane, M., Baxter, E., Sallade, S., Kellen, D., et al. (2019). Effects of word overlap on generalized gains from a repeated readings intervention. J. School Psychol. 74, 1-9. doi: 10.1016/j.jsp.2019.05.002

Messer, D., and Nash, G. (2017). An evaluation of the effectiveness of a computerassisted reading intervention. J. Res. Read. 41, 140-158. doi: 10.1111/14679817.12107

Moser, G. P., Morrison, T. G., and Wilcox, B. (2017). Supporting fourth-grade students' word identification using application software. Read. Psychol. 38, 349-368. doi: 10.1080/02702711.2016.1278414 
Nagler, T., Korinth, S. P., Linkersdörfer, J., Lonnemann, J., Rump, B., Hasselhorn, M., et al. (2015). Text-fading based training leads to transfer effects on children's sentence reading fluency. Front. Psychol. 6:119.

Niedo, J., Lee, Y., Breznitz, Z., and Berninger, V. W. (2014). Computerized silent reading rate and strategy instruction for fourth graders at risk in silent reading rate. Learn. Disabil. Q. 37, 100-110. doi: 10.1177/073194871350 7263

Pennington, B., and Lefly, D. (2001). Early reading development in children at family risk for Dyslexia. Child Dev. 72, 816-833. doi: 10.1111/1467-8624.00317

PISA (2012). Results: What Students Know and Can do. France: OECD.

Porta, M. E., and Ramirez, G. (2019). The impact of an early intervention on vocabulary, phonological awareness, and letter-sound knowledge among Spanish-speaking kindergarteners. Int. J. Sch. Educ. Psychol. 1, $1-15$.

Raspin, S., Smallwood, R., Hatfield, S., and Boesley, L. (2019). Exploring the use of the ARROW literacy intervention for looked after children in a UK local authority. Educ. Psychol. Pract. 35, 1-13.

Rao, V. C. (2018). English spelling and pronunciation: a brief study. J. Res. Sch. Profess. Eng. Lang. Teach. 2, 1-10.

Richardson, U., and Lyytinen, H. (2014). The graphogame method: the theoretical and methodological background of the technology-enhanced learning environment for learning to read. Hum. Technol. 10, 39-60. doi: 10.17011/ht/urn.201405281859

Rodrigues, M. L., Alçada, I., Calçada, T., and Mata, J. (2017). Apresentação de Resultados do Projeto Aprender a ler e a Escrever em Portugal [Presentation of the results of the project learning how to read and write in Portugal] Lisbon. Available Online at: http://www.dgeec.mec.pt/np4/292/ $\% 7 \mathrm{~B} \backslash$ protect $\backslash \mathrm{T} 1 \backslash$ textdollarclientServletPath\%7D/?newsId=516\&fileName= relatorio_progresso.pdf (accessed January 14, 2021).

Rosas, R., Escobar, J.-P., Ramírez, M.-P., Meneses, A., and Guajardo, A. (2017). Impact of a computer-based intervention in Chilean children at risk of manifesting reading difficulties. Infancia y Aprendizaje 40, 158-188. doi: 10. 1080/02103702.2016.1263451

Saine, N. L., Lerkkane, M., Ahonen, T., Tolvanen, A., and Lyytinen, H. (2011). Computer-assisted remedial reading intervention for school beginners at risk for reading disability. Child Dev. 82, 1013-1028. doi: 10.1111/j.1467-8624.2011. 01580.x

Schaars, M., Segers, E., and Verhoeven, L. (2017). Predicting the integrated development of word reading and spelling in the early primary grades. Learn. Individ. Differ. 59, 127-140. doi: 10.1016/j.lindif.2017.09.006

Schneider, D., Chambers, A., Mather, N., Bauschatz, R., Bauer, M., and Doan, L. (2016). The effects of an ICT-based reading intervention on students' achievement in grade two. Read. Psychol. 37, 793-831. doi: 10.1080/02702711. 2015.1111963

Serrano, F., Genard, N., Sucena, A., Defior, S., Alegria, J., Mousty, P., et al. (2011). Variations in reading and spelling acquisition in Portuguese, French and Spanish: a cross-linguistic comparison. J. Portug. Linguist. 10, 183-204.

Seymour, P. H. K., and Evans, H. M. (1999). Foundation level dyslexias: assessment and treatment. J. Learn. Disabil. 32, 394-405. doi: 10.1177/ 002221949903200505

Seymour, P. H. K., Aro, M., and Erskine, J. (2003). Foundation literacy acquisition in European orthographies. Br. J. Psychol. 94, 143-174. doi: 10.1348/ 000712603321661859

Shannon, L. C., Styers, M. K., Wilkerson, S. B., and Peery, E. (2015). Computerassisted learning in elementary reading: a randomized control trial. Comput. Sch. 32, 20-34. doi: 10.1080/07380569.2014.969159

Snellings, P., van der Leij, A., de Jong, P. F., and Blok, H. (2015). Enhancing the reading fluency and comprehension of children with reading disabilities in an orthographically transparent language. J. Learn. Disabil. 42, 291-305. doi: 10.1177/0022219408331038

Snowling, M. (2014). Dyslexia: a language learning impairment. J. Br. Acad. 2, 43-58.

Snowling, M., and Hulme, C. (2011). Evidence-based interventions for reading and language difficulties: creating a virtuous circle. Br. J. Educ. Psychol. 81, 1-23. doi: $10.1111 / j .2044-8279.2010 .02014 . x$

Solheim, O., Frijters, J., Lundetrae, K., and Uppstad, P. (2018). Effectiveness of an early reading intervention in a semi-transparent orthography: a group randomised controlled trial. Learn. Instr. 58, 65-79. doi: 10.1016/j.learninstruc. 2018.05.004
Stanovich, K. E. (1991). "Changing models of reading and reading acquisition," in Learning to Read: Basic Research and its Implications eds L. Rieben and C. A. Perfetti (Mahwah: Lawrence Erlbaum Associates, Inc.), 19-31.

Sucena, A., and Castro, S. L. (2011). ALEPE - Avaliação da Leitura em Português Europeu. Banco Finantia: CEGOC.

Sucena, A., Castro, S. L., and Seymour, P. (2009). Developmental dyslexia in an orthography of intermediate depth: the case of European Portuguese. Read. Writ. 22, 791-810. doi: 10.1007/s11145-008-9156-4

Sucena, A., Cruz, J., Viana, F. L., and Silva, A. F. (2015). "Graphogame Português alicerce: software de apoio a crianças disléxicas," in Proceedings of the 17th European Conference on Developmental Psychology, eds M. J. Gomes, A. J. Osório, and L. Valente (Braga: Universidade do Minho).

Sucena, A., Marques, C., Silva, A. F., Ramalho, A., Machado, A. R., Santos, A. R., et al. (2019). "I read": reading and writing skills promotion software," in ARTECH 2019 Proceedings of the: 9th International Conference on Digital and Interactive Arts, eds P. Arantes and J. V. Sá (Braga: Portugal).

Suggate, S. (2016). A Meta-analysis of the long-term effects of phonemic awareness, phonics, fluency, and reading comprehension interventions. J. Learn. Disabil. 49, 77-96. doi: $10.1177 / 0022219414528540$

Tabachnick, B. G., and Fidell, L. S. (2013). Using Multivariate Statistics. London: Pearson.

Taha, H., and Saiegh-Haddad, E. (2015). The role of phonological versus morphological skills in the development of Arabic spelling: an intervention study. J. Psycholinguist Res. 45, 507-535. doi: 10.1007/s10936-015-9362-6

van de Ven, M., de Leeuw, L., van Weerdenburg, M., and Steenbeek-Planting, E. G. (2017). Early reading intervention by means of a multicomponent reading game. J. Comput. Assist. Learn. 33, 320-333. doi: 10.1111/jcal.12181

Verdasca, J., Neves, A. M., Fonseca, H., Fateixa, J. A., Procópio, M., and MagroC, T. (2019). Relatório PNPSE 2016-2018: Escolas e Comunidades Tecendo Políticas Educativas com base em Evidências [Schools and Communities Making Evidence-Based Educational Policies]. PNPSE. Available online at: https://dspace.uevora.pt/rdpc/bitstream/10174/25940/1/Escolas\%20e\% 20Comunidades\%20tecendo\%20Pol\%C3\%ADticas\%20Educativas\%20com\% 20base $\% 20$ em\%20Evid\%C3\%AAncias\%20\%28Relat\%C3\%B3rio\%20PNPSE\% 202016-2018\%29.pdf (accessed January 15, 2021).

Viana, F. L., and Sucena, A. (2014). "A avaliação da leitura: necessidades, complexidades e instrumentos," in Alfabetização em Países de Língua Portuguesa: Pesquisa e Intervenção [Literacy in Portuguese-Speaking Countries: Research and Intervention], eds J. P. Oliveira, T. M. S. Braga, F. L. P. Viana, and A. Sucena (Brazil: Editora CRV), 67-84.

Volkmer, S., Galuschka, K., and Schulte-Körne, G. (2019). Early identification and intervention for children with initial signs of reading deficits - a blinded randomized controlled trial. Learn. Instr. 59, 1-12. doi: 10.1016/j.learninstruc. 2018.09.002

Williams, K., Walker, M., Vaughn, S., and Wanzek, J. (2016). A synthesis of reading and spelling interventions and their effects on spelling outcomes for students with learning disabilities. J. Learn. Disabil. 50, 286-297. doi: 10.1177/ 0022219415619753

Wimmer, H., and Mayringer, H. (2002). Dysfluent reading in the absence of spelling difficulties: a specific disability in regular orthographies. J. Educ. Psychol. 94, 272-277. doi: 10.1037/0022-0663.94.2.272

Zalewska-Łunkiewicz, K., Józefacka-Szram, N., Biskupek, L., Gryl, L., Sikora, M., and Suchowska, S. (2016). Cohesion, flexibility, communication and socioeconomic status of families and cognitive 448 development in preschool and early school-age children. J. Psychiatry Clin. Psychol. 16, 246-255.

Ziegler, J. C., Bertrand, D., Tóth, D., Csépe, V., Reis, A., Faisca, L., et al. (2010). Orthographic depth and its impact on universal predictors of reading: a cross language investigation. Psychol. Sci. 21, 551-559. doi: 10.1177/0956797610363

Conflict of Interest: The authors declare that the research was conducted in the absence of any commercial or financial relationships that could be construed as a potential conflict of interest.

Copyright (C) 2021 Sucena, Silva and Marques. This is an open-access article distributed under the terms of the Creative Commons Attribution License (CC BY). The use, distribution or reproduction in other forums is permitted, provided the original author(s) and the copyright owner(s) are credited and that the original publication in this journal is cited, in accordance with accepted academic practice. No use, distribution or reproduction is permitted which does not comply with these terms. 